Ophthalmologe 2019 $\cdot 116$ (Suppl 1):S21-S24 https://doi.org/10.1007/s00347-018-0781-2 Published online: 6 September 2018

(c) Springer Medizin Verlag GmbH, ein Teil von Springer Nature 2018

CrossMark
Deutsche Ophthalmologische Gesellschaft (DOG)

Deutsche Ophthalmologische Gesellschaft, Munich, Germany

\section{March 2018}

\section{Preamble}

As a scientific society, one of the most important tasks of the Deutsche Opthalmologische Gesellschaft (DOG) is to promote ophthalmological research and science. This includes the promotion of researchers and research groups and their specific projects, as well as the support of institutions and organisations that conduct ophthalmic research. The resources available for ophthalmic research are scarce; therefor one should strive to use these resources as efficiently as possible. To support research institutions and their sponsors, the DOG issues the following recommendations which should serve as a guide for resource- and budget-planning in clinical trials and non-interventional clinical studies.

\section{Main contact person in multicenter studies}

In multicenter studies, it is beneficial for both the participating study centers and for the sponsor (or a contract research organization [CRO] designated by them), to name a main contact person among the German investigators (a Coordinating Investigator or formerly LKP) as early as possible. It is recommended that such a main contact person be named after the "Pre-Study Visit" or the "Site Selection Visit". This person can first inquire which study centers will participate in

The German version of this article can be found under https://doi.org/10.1007/s00347018-0738-5. the study, or clarify whether he/she can negotiate on behalf of all participating German centers. For the participating centers, as well as for the sponsor/CRO, this can mean significant savings in time and expenditure. If necessary, the experts of the work group 'AG DOG-Klinische Studienzentren' are available to advise the clinical study centers.

For all parties involved, it is advantageous to start the negotiations as early as possible. It is helpful if the main contact person agrees with the sponsor on a uniform study budget for all sites, whereby deviations could occur, for example, due to differences in deliverables or additional services that a center has to provide. Different overhead rates at the centers (see below) can also lead to budget differences. In order to fully cover all the expenditure referred to in point 2 , it is advisable for the sponsor to list the envisaged individual procedures and agree upon a specific remuneration for each of them (using the flowchart of visits and procedure, for example). A clear improvement in the budgeting reliability for both the study sites and the sponsor can thus be achieved, in comparison to compensation by means of lump sums per visit.

\section{Guide for calculating study budgets}

The basis for budget considerations is usually the study protocol, and possibly manuals, documentation sheets (worksheets) and/or e-CRF, in which all planned procedures and study services are listed. This range of services should be comprehensively analyzed and evaluated, whereby the following conditions should be adhered to.

\subsection{EU directive}

First and foremost, all budget negotiations must comply with the EU directive "Community framework for state aid for research, development and innovation" (point 3.2.1., Research on behalf of companies [contract research or research services]). It states that the services provided by public institutions to third parties, also e.g. for industrial companies, have to be cost covering and with a profit margin.

\subsection{Higher expenditure for ophthalmological deliverables}

Ophthalmological examinations, procedures and treatments performed in clinical trials can be significantly more costly than those in daily clinical practice. The study site, as well as the sponsor should seek adequate remuneration for these services.

Potential extra efforts could result from:

a. greater amount of time for protocolcompliant examinations, procedures, treatments,

b. higher demand on the staff; they must usually demonstrate specific qualifications to be able to participate in clinical trials at all, and be explicitly registered, trained and certified for the relevant study; and 
c. considerably more elaborate documentation and evaluation of the obtained data.

\subsection{Additional staff and cost areas}

Moreover, allowance should be made for increased expenditure resulting from additionally required staff, e.g. for investigators, masked/unmasked study assistants or study coordinators and their deputies (at least one "back-up" is required), which should be considered in budget planning.

As well as patient and service-related expenses, other potential cost areas must be considered. These may be for recruiting patients (database queries, file studies, keeping so-called pre-screening lists), documenting study data in the eCRF, processing and forwarding data to evaluation centers, so-called reading centers and medications. Furthermore, the GCP(Good Clinical Practice)-compliant archiving of study documents, as well as communication and correspondence with $\mathrm{CRO} /$ sponsor during the course of studies, can also cause costs, which must be considered.

Depending on the catchment area of the study center, sufficient patient travel expenses are significant in budget planning. If e.g. during elaborate visits, an expense allowance is provided for patients, which is permissible under European and national law, they should also be taken into account.

\subsection{Costs for monitoring, audits and training during the study}

An unforeseeable significantly higher amount of time can be incurred in study sites with monitoring (in particular with a change in monitors or socalled "remote monitoring"), with audits and inspections (and their preparation), as well as additional training measures during the study. An hourly rate should be agreed upon for these services for all participating members of the study team, according to which this additional time can be billed.

It is also advisable for sponsors and sites to agree that audits be announced at least two weeks in advance. In the case of shorter deadlines, a considerable additional expense would be expected because then the appropriate capacity reserves would have to be available on an ongoing basis-and further charged.

\subsection{Cost of study set-up}

Even in the study preparation phase, costs can be significant, e.g. because staff resources have to be provided for longer periods of time (preparing curricula vitae [CVs], maintaining qualification logs and other documents). For such cases, it is advisable to consider a study preparation fee (so-called "set-up fee"). Study preparation also often involves extensive training and certification, e.g. planning an "Investigators' Meeting", on-site at the center or online. The sponsor should provide, in advance, an overview of the calculations for adequate remuneration for these trainings and certifications, including the time required for the planned activities. These costs can also be included in the calculation of the set-up fee. In this context, appropriate hourly rates should be agreed upon at an early stage.

\subsection{Facility and administrative (F\&A) costs (overhead)}

This refers to indirect/direct costs that cannot be directly attributed to a project but arise when carrying out clinical studies, through the use of rooms, electricity, heating, telephone, cleaning, administrative and technical personnel, etc.

The legal basis of a university's claim for compensation for these direct costs arises from German legislation (see, for example, the Higher Education Act of the State of North Rhine-Westphalia $\$ 71$ [Research with Third-Party Funds], paragraph 3, sentence 2; Law governing the Universities of Baden-Württemberg $₫ 41$ [Research with Third-Party Funds], paragraph 5, sentence 1).

In the course of budget negotiations, it should be clarified with the sponsor at an early stage whether F\&A costs should be allocated to individual procedures or whether they should be reported separately in the budget. Since different overhead costs are incurred/charged at the individual sites, a separate listing of the F\&A costs in the budget should be strived for. In doing so, the sponsor should be informed at an early stage (see point 1) that different overhead rates are charged at individual sites and that it is desirable that this budget item is adjusted according to location.

\subsection{Early termination}

Since, especially in the early stages of the clinical trial of new therapeutic approaches, there is a risk for the study site that the study or even the overall development of a new therapy is terminated, an early termination fee should be agreed upon. This flat fee also includes compensation for resources that are made available to carry out the study and thus cannot be used for other projects in the short term (opportunity costs).

If the sponsor considers it reasonable to start services at the site prior to concluding the trial contract, such as training, because of time demands, it is advisable to have already agreed upon the remuneration for these pre-contractual services and to have them guaranteed in a written letter of intent. Otherwise, the service providers may consider providing the services in question only after conclusion of the contract, because in the case of a termination of the trial/development before conclusion of the contract, there is no written basis underlying the claim for the billing of these services.

\subsection{Serious adverse events}

It is advisable to agree at the beginning of the study on how to handle the treatment of serious adverse events (SAEs), their documentation, follow-up and termination because the expenditure involved can often be significantly higher than that involved in complication-free procedures. It is appropriate here, to agree on a lump sum, which can be calculated separately per event, for example. Alternatively, it can also be stipulated here that remuneration is paid according to the appropriate hourly rates. 


\section{3 "Consultation studies"}

These are studies in which an ophthalmological center is available as a 'subcenter' for examinations performed for clinical studies of other departments. Here, the same recommendations as for primary ophthalmological studies could be used in the budget calculation. It is important to work towards the earliest involvement of the ophthalmological department within the respective medical center. In addition, a separate contract or at least a corresponding supplement to the investigator's contract should be made for the ophthalmologic center, which then allows a separate billing of the "subcenter" to the sponsor. For consultation studies, a detailed list and description of the required procedures as a basis for budget preparation can also facilitate the negotiation process.

Revised version of the DOG Task Force "Clinical Study Centers"

Spokeswoman: Prof. Dr. med. Barbara Wilhelm

Deputy Speaker: Prof. Dr. med. Monika Fleckenstein

Tübingen/Bonn, August 2018

Editorial board. Prof. Dr. Barbara Wilhelm, Universitäts-Augenklink Tübingen (in charge of the report)

Prof. Dr. Monika Fleckenstein, Universitäts-Augenklinik Bonn (in charge of the report)

Prof. Dr. Daniel Böhringer, Universitäts-Augenklinik Freiburg

Prof. Dr. Christoph Deuter, Universitäts-Augenklinik Tübingen

Prof. Dr. Nicolas Feltgen, Universitäts-Augenklinik Göttingen

PD Dr. Dr. Katrin Lorenz, Universitäts-Augenklink Mainz

Dr. Tobias Peters, Universitäts-Augenklinik Tübingen

Dr. Amelie Pielen, Universitäts-Augenklink Hannover

\section{Corresponding address}

Deutsche Ophthalmologische Gesellschaft (DOG)

Deutsche Ophthalmologische Gesellschaft Platenstr. 1, 80336 Munich, Germany

geschaeftsstelle@dog.org

\section{Compliance with ethical guidelines}

Conflict of interest. See - Table 1 in the appendix.

This article does not contain any studies with human participants or animals performed by any of the authors.

The supplement containing this article is not sponsored by industry. 


\section{Appendix}

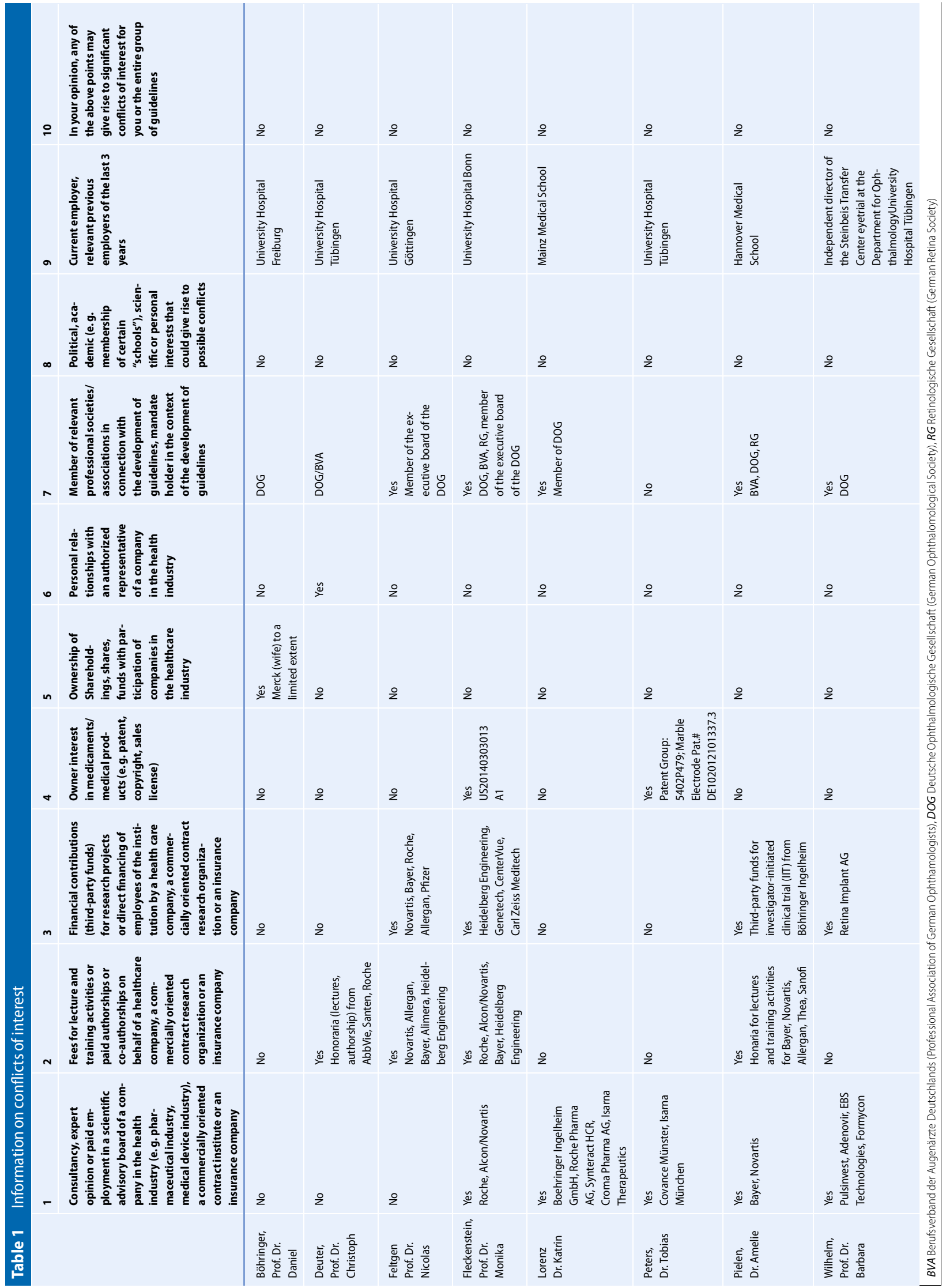

